\title{
L'Hospitalité des savoirs. Mélanges offerts à Alain Montandon, sous la direction de Pascale Auraix- Jonchière, Jean-Pierre Dubost, Éric Lysoe, Anne Tomiche
}

\section{Florence Fix}

\section{(2) OpenEdition}

\section{Journals}

Édition électronique

URL : http://journals.openedition.org/studifrancesi/3755

DOI : 10.4000/studifrancesi.3755

ISSN : 2421-5856

Éditeur

Rosenberg \& Sellier

Édition imprimée

Date de publication : 1 décembre 2012

Pagination : $574-575$

ISSN : 0039-2944

\section{Référence électronique}

Florence Fix, "L'Hospitalité des savoirs. Mélanges offerts à Alain Montandon, sous la direction de Pascale Auraix-Jonchière, Jean-Pierre Dubost, Éric Lysoe, Anne Tomiche», Studi Francesi [En ligne], 168 (LVI | III) | 2012, mis en ligne le 30 novembre 2015, consulté le 07 mars 2021. URL : http:// journals.openedition.org/studifrancesi/3755; DOI : https://doi.org/10.4000/studifrancesi.3755

Ce document a été généré automatiquement le 7 mars 2021.

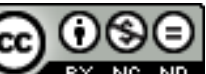

Studi Francesi è distribuita con Licenza Creative Commons Attribuzione - Non commerciale - Non opere derivate 4.0 Internazionale. 
L'Hospitalité des savoirs. Mélanges offerts à Alain Montandon, sous la direction de Pascale AuraixJonchière, Jean-Pierre Dubost, Éric
Lysoe, Anne Tomiche

Florence Fix

\section{RÉFÉRENCE}

AA. VV., L'Hospitalité des savoirs. Mélanges offerts à Alain Montandon, sous la direction de Pascale AURAIX-JONCHIÈRE, Jean-Pierre DUBOST, Éric LYSOE, Anne TOMICHE, ClermontFerrand, Presses Universitaires Blaise-Pascal, 2011, pp. 853.

1 En hommage à Alain Montandon, professeur de littérature comparée durant plus de trente ans à l'Université de Clermont-Ferrand, se trouvent réunis par ses collègues dans L'Hospitalité des savoirs quarante-sept articles relatifs à cette notion dont il fut l'un des pionniers en France (on se souvient de Désirs d'hospitalité. De Homère à Kafka, P. U. F., 2002, traduction italienne chez Salerno Editrice en 2004). Si le rayonnement du chercheur et de l'enseignant sont mis en valeur par la grande quantité et diversité de textes regroupés en quatre rubriques, certaines thématiques, d'autres méthodologiques ou génériques - civilité, hospitalité et amitié tout d'abord, romantismes ensuite, puis sociopoétique et anthropologie culturelle, enfin mythes et formes littéraires - le lecteur doit accepter de se plier à un va-et-vient entre roman, lettres, théâtre, contes, récits autobiographiques. La lecture est plaisante, déclinant les satisfactions de la course à pied ou de la promenade, évoquant l'art de vieillir, le rire, la mode, la cuisine, la valse ou encore des figures mythiques comme Lilith ou Caïn. Aussi foisonnant et disparate soit-il, cet ouvrage témoigne de tant de vivacité et de joie intellectuelle que le 
lecteur saura l'accompagner dans sa dilatation sur huit siècles (du Jeu de la Feuillée à l'extrême contemporain) et divers espaces géographiques et langues, affirmant pleinement la démarche comparatiste du propos.

Relèvent de la période 1800-1850 plusieurs articles de grande qualité, notamment sur Théophile Gautier (auquel, rappelons-le, Alain Montandon a consacré une biographie publiée aux éditions Aden en 2011): Patrick BERTHIER (Quelle amitié entre Balzac et Gautier?, pp. 161-181) défend que l'estime mutuelle que se portaient les deux écrivains n'allait point sans une "exploitation» de Gautier par Balzac en vue de l'aider à publier, voire à compléter certains de ses textes. L'emprunt, l'influence, l'émulation dont les universitaires font leur miel ont leur revers de fiel: «l'admiration pure, entre artistes, n'existe pas, et se mêle d'envie à la mesure de son intensité». Sans doute est-ce là la raison des liens durables de Delacroix, qui fut toute sa vie fidèle à ses amis de jeunesse: ils n'étaient pas artistes, comme le souligne Marie-Christine NATTA (Eugène Delacroix et la religion de l'amitié, pp. 183-193). Très stimulant également est l'article d'Anne GEISLERSZMULEwicz (Gautier et la mode de son temps, pp. 537-552) qui dépasse le portrait de l'artiste en gilet rouge dédaigneux envers les habits noirs afin de démontrer que Gautier défend dans ses textes sur la mode des «positions esthétiques tout à fait congruentes avec sa critique d'art et avec sa critique littéraire», dans un même «catéchisme esthétique». Paolo TORTONESE (La ressemblance. Notes sur Gautier et Hoffmann, pp. 525-534) invite à une variation sur le thème de la copie picturale à travers plusieurs œuvres fantastiques, mais somme toute fort peu sur Gautier. Serge ZeNKINE (Théophile Gautier: de la vie artistique à l'écriture artiste, pp.553-570) pose en revanche très adroitement que le comportement artiste doit beaucoup au canular, à l'escamotage et à la mascarade, que l'œuvre littéraire de Gautier fait dériver en une «sublimation esthétique» qui en minore l'agressivité.

3 On lira également avec plaisir l'article d'Hélène LAPLACE-CLAVERIE (Musset et la valse, pp. 583-593) qui rappelle que la valse fut une danse révolutionnaire, rompant avec le menuet aristocratique, et constituant chez Musset un moment charnière de l'économie narrative, tout autant qu'un motif esthétique récurent, fascinant parce que contradictoire.

4 Les figures mythiques qui occupèrent beaucoup la recherche d'Alain Montandon sont présentes dans ce volume avec deux articles notamment: Aspects du caïnisme romantique de Véronique LÉONARD-ROQUES (pp.615-632), spécialiste du sujet, étudie Caïn dans plusieurs réécritures européennes au sein desquelles on pourra retrouver des rapprochements entre Leconte de Lisle, Hugo, Baudelaire et Nerval; dans "Jeanne" de George Sand, Jeanne d'Arc romantique?, Simone BERNARD-GRIFFITHS (pp.633-656) a l'heureuse démarche d'étudier dans ce «roman de contrastes» les nombreux déplacements de la figure historique vers le rustique sandien.

On tient enfin, même si le corpus d'étude dépasse largement notre propos, à attirer la curiosité du lecteur vers l'article de Myriam ROMAN (Sociopoétique de la concierge XIXe-XX siècles, pp. 241-255) qui contient de belles pages sur le portier balzacien, ainsi que sur les gardiens chez Henry Monnier et Eugène Sue, détenteurs de l'autorisation de passage de la rue à l'espace privé - dont le portrait hostile ou comique méconnaît toutefois la misère. 